UDC 616-006.48; 614.1:614.71

DOI: $10.21668 /$ health.risk/2020.3.21.eng

Read

online

Review

\title{
PRIMARY CNS TUMORS IN ADULTS AND ENVIRONMENTAL FACTORS: AN UPDATE
}

\section{S.G. Berntsson}

Uppsala University Hospital, SE-751 85, Uppsala, Sweden

\begin{abstract}
The incidence of adult primary brain tumors is increasing in some European countries.
High-dose ionizing irradiation, rare genetic syndromes, and genetic predisposition in $5 \%$ of families are a few established environmental risk factors for brain tumor.

Mobile phone use that causes near brain exposure to radiofrequency electromagnetic waves and thus creates risks of CNS tumors has been the focus of many studies.

Nine meta-analyses were available on this subject. The Interphone multi-center case-control study is the largest one to date; it included 2.708 glioma and 2.409 meningioma cases and matched controls in 13 countries. Studies exploring metals (cadmium, lead), pesticides, outdoor pollution, virus, and risk of glioma created by exposure to them were reviewed.

Interphone study did not show increased risk of glioma or meningioma in mobile-phone users. One recent metaanalysis in 2017 found that prolonged exposure i.e.,> 10 years of all phone types was associated with increased risk of ipsilateral CNS tumor locations. In another meta-analysis, long-term use of mobile-phones was found to be a risk factor for lowgrade glioma. In case of all durations regarding mobile phone use and both sides of the head, the results of pooling data were more discordant. A large prospective study in 2014 showed that long term use vs never use increased risks of acoustic neurinoma $(10+$ years: $R R=2.46,95 \% C I=1.07-5.64, P=0.03)$, but not of glioma or meningioma. Studies of other risk factors showed no/weak/contradictory association with brain tumor risk.

In the absence of robust and consistent evidence, a causal relation between radiofrequency exposure and CNS tumors was not found. Large prospective studies of this kind regarding a disease with low incidence require a high number of participants and a long follow-up period.
\end{abstract}

Key words: brain tumor, glioma, meningioma, environmental risk factors.

Gliomas account for more than $70 \%$ of all adult primary brain tumors. According to the 2016 World Health Organization (WHO) classification of CNS tumors, diffuse gliomas include the WHO grade II and grade III astrocytic tumors, grade II and grade III oligodendrogliomas, and the grade IV glioblastomas [1]. Malignancy ranges from grade IIV, with grade IV glioblastoma being the most malignant form of gliomas. The prognosis remains dismal for patients with glioblastoma, despite advances in surgery, radiotherapy, and chemotherapy with a median survival time of 9-15 months. Anaplastic grade III WHO gliomas have a median survival time of 1.6 years, and low-grade WHO grade II gliomas that have a more in- dolent course and grow slowly have a median survival time of 5-10 years [2].

Meningiomas that account for approximately $20 \%$ of all primary brain tumors are the second most common tumors with incidence rates of 3-4 cases per 100,000 males per year and 9-13 cases per 100,000 females per year [3]. Most meningiomas grow slowly, are asymptomatic, and are discovered by accident. According to the 2016 WHO classification of brain tumors, they are regarded as grade I, meaning benign tumors [1]. The presence of brain invasion, necrosis, high cellularity, and prominent nuclei are among the histological features that classify a diagnosis of WHO grade II, atypical meningioma [1].

(C) Berntsson S.G., 2020

Shala Ghaderi Berntsson - MD, PhD, Associate Professor, Senior Consultant Department of Neurology (e-mail: shala.berntsson@neuro.uu.se; tel.: +46 18611 00; ORCID: https://orcid.org/0000-0002-2251-5879). 
Meningiomas larger than $2.5-3 \mathrm{~cm}$ usually cause symptoms. Unpredictable and different clinical behavior of meningiomas causes difficulties in assessing mortality and morbidity rates. Estimates of 5-year survival usually range from $73 \%$ to $94 \%$ [4].

The annual incidence of glioma has remained relatively stable since 1983, despite the high prevalence of mobile phone use [5]. However, an increasing trend in the incidence of gliomas has been observed in some European countries. The annual incidence of glioblastoma more than doubled in England between 1995-2015 [6].

Epidemiological studies are of great importance in identifying risks that contribute to the development of CNS neoplasms.

Apart from the well-known risk caused by high-dose ionizing irradiation and classified as a group 1 carcinogen, the genetic predisposition in about $5 \%$ of families, and rare genetic syndromes, there are few established environmental risk factors for glioma [7]. When treating 10,834 Israeli patients with cranial and cervical irradiation with a mean dose of 1-6 Gy for tinea capitis the relative risk for developing a tumor or a glioma after a latency of $>30$ years increased by 6.9 and 2.6 respectively. This was the first conclusive evidence of an association between ionizing radiation and brain tumors [8]. A 6.5-fold increase in meningioma risk was reported among residents of Hiroshima following the nuclear attack of 1945 [9].

More evidence for Ionizing radiation as an established carcinogen is based on follow-up studies performed on patients who underwent radiotherapy for cancer treatment during childhood, where odds ratios (OR's) equal to 6.78 and 9.94 were reported for glioma and meningioma respectively [10]. Regarding diagnostic head CT scans during childhood, recent follow-up studies of children and adolescents reported an excess RR for brain tumor as large as 23 per Gy [11]. However, to date, no association between CT scans of the head and cancer risk in adults has been established.

Nonionizing radiation in terms of near brain exposure to radiofrequency electromagnetic waves on mobile phones and risks of CNS tumors has been the focus of many studies. By the end of 2018, 67\% of the global population was subscribed to mobile services.

The INTERPHONE study, which was coordinated by the International Agency for Research on Cancer (IARC), was the largest multinational study investigating a possible association between carcinogenic risks of tumors in the head and neck regions and radiofrequency fields emitted by mobile phones [12]. This multi-center case-control study included 2,708 glioma and 2,409 meningioma cases as well as matched controls in 13 countries. The results did not show increased risk of glioma or meningioma in the whole population of mobilephone users [13].

To date, nine meta-analyses have been published on this subject, mostly based on studies from the INTERPHONE group. The main brain cancer typesincluded in the study were glioma, meningioma, and acoustic neurinoma.

Two recent meta-analyses in 2017 found that prolonged exposure i.e.,> 10 years toall phone types was associated with increased risks of ipsilateral CNS tumor locations, and the long-term use of mobile-phones was found to be a risk factor for low-grade glioma [14-16]. Low-grade gliomas are known to grow slowly and have a long latency period, usually affecting younger patients. Indeed, considering the natural history of low-grade glioma, it is important to keep in mind that this type of tumor may possess different carcinogenic mechanisms as well as different risk factors compared to glioblastoma.

In case of all durations regarding use and both sides of the head, the results of pooling data were more discordant. A large prospective study showed that long term mobile 
phone use limited to 10 years vs those who never used a mobile resulted in increased risks of acoustic neurinoma $(10+$ years: $\mathrm{RR}=2.46,95 \% \mathrm{CI}=1.07-5.64, \mathrm{P}=0.03)$, but not of glioma or meningioma.

In the absence of robust and consistent evidence, a causal relation between radiofrequency exposure and CNS tumors was not found. The only evidence is for an association among long-term users with acoustic neurinoma. Large prospective studies of this kind on a disease with low incidence require a high number of participants and a long follow-up period. Another limitation is how to quantify the level of exposure, depending on a phone type and generation, in addition patterns of mobile phone use change over time. These factors partially explain the limited quality of studies included in meta-analyses. As a result of conflicting scientific evidence, the IARC classified radiofrequency electromagnetic waves in the group $2 \mathrm{~B}$, which means possible carcinogens.

$\mathrm{N}$-nitroso compounds (NOCs) are known to be potent carcinogens in animal models. Nitrosamines can form endogenously from foods, and are present in cured meat, tobacco, cosmetics, automobile interiors and drugs such as diuretics, antihistamines, antibiotics, tranquilizers, and narcotics. The observations from animal studies suggested a hypothesis of NOCs as a possible risk factor of brain tumor. The most recent studies are from a decade ago; three prospective studies evaluating consumption of red processed and cured meats did not reveal increased risks of glioma [17-19]. One case-control study investigating transplacental exposure to ethylnitrosurea through maternal diet during pregnancy and risk of brain tumors in childhood showed OR equal to 1.8 for astrocytomas [20]. Studies of this kind do not allow definitive conclusions due to recall and selection bias.

Regarding metals, cadmium as a type 1 carcinogen has been associated with a variety of cancers. However, any evidence for an association with brain tumor risk is weak, and based on only one study [21]. Casecontrol studies focusing on exposure to lead in the highest quantities revealed slightly increased risks of brain tumor [22].

A possibility of an association between exposure to pesticides and the higher risk of CNS cancers in farmers has been explored in several case-control studies with contradictory results [23]. A cohort study of nearly 200,000 French farmers showed higher risk of CNS tumors in farmers exposed to pesticides, where the greatest increases in risks of meningioma were detected for pig farmers and those growing sunflowers, beets and potatoes. For farmers growing grasslands there were increased risks of gliomas [24].

Outdoor air pollution was classified as a carcinogenic factor by IARC in 2013. Outdoor air pollution has been associated with increased risk of ischemic stroke, Parkinson disease, and has shown a strong causal association with lung cancer. Fine microparticles from pollution such as Particulate matter (PM) and $\mathrm{O}_{3}$ have been recognized as the most important risk factors to public health [25].

However, the data on brain tumors do not provide evidence for an association with outdoor air pollution, mainly due to small numbers of such studies and conflicting results. Interestingly, a study found a negative association between exposure to air pollution and CNS cancer mortality [26]. The protective effect was suggested to be induced by immune hyperactivity that was characteristic for allergy and asthma. An inverse association between self-reported allergies and gliomas has been confirmed in previous studies [27, 28].

Regarding associations between viruses and risks of glioma, previous studies identified polyomavirus, including JC virus, BK virus, and Simian virus -40 in human glioma but an association was not confirmed [29]. Human cytomegalovirus (HCMV) being carried by the majority of people world- 
wide is the major infectious cause of developmental disorders in the CNS [30].

The presence of CMV genomic expression and protein material in human glioma samples has been well documented [31, 32]. Trials with anti-viral therapy have failed to improve survival in these patients. However, immunotherapy has been used to target CMV antigens in patients with glioblastoma with promising initial results.

In conclusion, identifying the potential risk factors for brain tumors is extremely important due to devastating consequences of the disease. The low incidence of brain tumors, the natural history of slowly growing patterns, difficulties in quantifying exposure to environmental factors, and recall bias remain the main challenges in designing prospective studies.

Funding. The research was not granted any sponsor support.

Conflict of interests. The authors declare there is no any conflict of interests.

\section{References}

1. Louis D.N., Perry A., Reifenberger G., Von Deimling A., Figarella-Branger D., Cavenee W.K., Ohgaki H. [et al.]. The 2016 World Health Organization Classification of Tumors of the Central Nervous System: a summary. Acta Neuropathol, 2016, vol. 131, no. 6, pp. 803-820. DOI: 10.1007/s00401-016-1545-1

2. Ohgaki H., Kleihues P. Epidemiology and etiology of gliomas. Acta Neuropathol, 2005, vol. 109, no. 1, pp. 93-108. DOI: 10.1007/s00401-005-0991-y

3. Larjavaara S., Haapasalo H., Sankila R., Helen P., Auvinen A. Is the incidence of meningiomas underestimated? A regional survey. Br. J. Cancer, 2008, vol. 99, no. 1, pp. 182-184. DOI: $10.1038 /$ sj.bjc. 6604438

4. Sughrue M.E., Rutkowski M.J., Aranda D., Barani I.J., McDermott M.W., Parsa A.T. Treatment decision making based on the published natural history and growth rate of small meningiomas. J. Neurosurg, 2010, vol. 113, no. 5, pp. 1036-1042. DOI: 10.3171/2010.3.JNS091966

5. Lonn S., Klaeboe L., Hall P., Mathiesen T., Auvinen A., Christensen H.C., Johansen C., Salminen T. [et al.]. Incidence trends of adult primary intracerebral tumors in four Nordic countries. Int. J. Cancer, 2004, vol. 108, no. 3, pp. 450-455. DOI: 10.1002/ijc.11578

6. Philips A., Henshaw D.L., Lamburn G., O'Carroll M.J. Brain Tumours: Rise in Glioblastoma Multiforme Incidence in England 1995-2015 Suggests an Adverse Environmental or Lifestyle Factor. J. Environ. Public. Health., 2018, vol. 2018, pp. 7910754. DOI: 10.1155/2018/7910754

7. Ohgaki H., Kleihues P. Population-based studies on incidence, survival rates, and genetic alterations in astrocytic and oligodendroglial gliomas. J. Neuropathol. Exp. Neurol., 2005, vol. 64, no. 6, pp. 479-489.

8. Ron E., Modan B., Boice J.D. Jr., Alfandary E., Stovall M., Chetrit A., Katz L. Tumors of the brain and nervous system after radiotherapy in childhood. N. Engl. J. Med., 1988, vol. 20, no. 319 (16), pp. 1033-1039. DOI: 10.1056/NEJM198810203191601

9. Shintani T., Hayakawa N., Kamada N. High incidence of meningioma in survivors of Hiroshima. Lancet, 1997, vol. 10, no. 349, pp. 1369. DOI: 10.1016/S0140-6736(05)63205-9

10. Neglia J.P., Robison L.L., Stovall M., Liu Y., Packer R.J., Hammond S., Yasui Y., Kasper C.E. [et al.]. New primary neoplasms of the central nervous system in survivors of childhood cancer: a report from the Childhood Cancer Survivor Study. J. Natl. Cancer. Inst., 2006, vol. 98, no. 21, pp. 1528-1537. DOI:10.1093/jnci/djj411

11. Pearce M.S., Salotti J.A., Little M.P., McHugh K., Lee C., Kim K.P., Howe N.L., Ronckers C.M. [et al.]. Radiation exposure from CT scans in childhood and subsequent risk of leukaemia and brain tumours: a retrospective cohort study. Lancet, 2012, vol. 4, no. 380, pp. 499-505. DOI: 10.1016/S0140-6736(12)60815-0

12. Cardis E., Richardson L., Deltour I., Armstrong B., Feychting M., Johansen C., Kilkenny M., McKinney P. [et al.]. The INTERPHONE study: design, epidemiological methods, and description of the study population. Eur. J. Epidemiol., 2007, vol. 22, no. 9, pp. 647-664. DOI: $10.1007 / \mathrm{s} 10654-007-9152-\mathrm{z}$ 
13. Group I.S. Brain tumour risk in relation to mobile telephone use: results of the INTERPHONE international case-control study. Int. J. Epidemiol., 2010, vol. 39, no. 3, pp. 675-694. DOI: 10.1093/ije/dyq079

14. Bortkiewicz A., Gadzicka E., Szymczak W.Mobile phone use and risk for intracranial tumors and salivary gland tumors - A meta-analysis. Int. J. Occup. Med. Environ. Health, 2017, vol. 30, no. 1, pp. 27-43. DOI: 10.13075/ijomeh.1896.00802

15. Yang M., Guo W., Yang C., Tang J., Huang Q., Feng S., Jiang A., Xu X., Jiang G. Mobile phone use and glioma risk: A systematic review and meta-analysis. PLoS One, 2017, vol. 12, no. 5, pp. e0175136. DOI: 10.1371/journal.pone.0175136

16. Benson V.S., Pirie K., Schuz J., Reeves G.K., Beral V., Green J. Million Women Study C. Mobile phone use and risk of brain neoplasms and other cancers: prospective study. Int. J. Epidemiol, 2013, vol. 42, no. 3, pp. 792-802. DOI: 10.1093/ije/dyt072

17. Dubrow R., Darefsky A.S., Park Y., Mayne S.T., Moore S.C., Kilfoy B., Cross A.J., Sinha R. [et al.]. Dietary components related to N-nitroso compound formation: a prospective study of adult glioma. Cancer Epidemiol Biomarkers Prev, 2010, vol. 19, no. 7, pp. 1709-1722. DOI: 10.1158/10559965.EPI-10-0225

18. Michaud D.S., Holick C.N., Batchelor T.T., Giovannucci E., Hunter D.J. Prospective study of meat intake and dietary nitrates, nitrites, and nitrosamines and risk of adult glioma. Am. J. Clin. Nutr., 2009, vol. 90, no. 3, pp. 570-577. DOI: 10.3945/ajcn.2008.27199

19. Terry M.B., Howe G., Pogoda J.M., Zhang F.F., Ahlbom A., Choi W., Giles G.G., Little J. [et al.]. An international case-control study of adult diet and brain tumor risk: a histology-specific analysis by food group. Ann. Epidemiol., 2009, vol. 19, no. 3, pp. 161-171. DOI: 10.1016/ j.annepidem.2008.12.010

20. Pogoda J.M., Preston-Martin S., Howe G., Lubin F., Mueller B.A., Holly E.A., Filippini G., Peris-Bonet R. [et al.]. An international case-control study of maternal diet during pregnancy and childhood brain tumor risk: a histology-specific analysis by food group. Ann. Epidemiol., 2009, vol. 19, no. 3, pp. 148-160. DOI: 10.1016/j.annepidem.2008.12.011

21. Wesseling C., Pukkala E., Neuvonen K., Kauppinen T., Boffetta P., Partanen T. Cancer of the brain and nervous system and occupational exposures in Finnish women. J. Occup. Environ. Med., 2002, vol. 44, no. 7, pp. 663-668.

22. Cocco P., Dosemeci M., Heineman E.F. Brain cancer and occupational exposure to lead. J. Occup. Environ. Med., 1998, vol. 40, no. 11, pp. 937-942. DOI: 10.1097/00043764-199811000-00001

23. Fallahi P., Elia G., Foddis R., Cristaudo A., Antonelli A. High risk of brain tumors in military personnel: a case control study. Clin. Ter., 2017, vol. 168, no. 6, pp. e376-e379. DOI: 10.7417/T.2017.2037

24. Piel C., Pouchieu C., Tual S., Migault L., Lemarchand C., Carles C., Boulanger M., Gruber A. [et al.]. Central nervous system tumors and agricultural exposures in the prospective cohort AGRICAN. Int. J. Cancer, 2017, vol. 141, no. 9, pp. 1771-1782. DOI: 10.1002/ijc.30879

25. Vienne-Jumeau A., Tafani C., Ricard D.Environmental risk factors of primary brain tumors: A review. Rev. Neurol. (Paris), 2019, vol. 175, no. 10, pp. 664-678. DOI: 10.1016/j.neurol.2019.08.004

26. McKean-Cowdin R., Barnholtz-Sloan J., Inskip P.D., Ruder A.M., Butler M., Rajaraman P., Razavi P., Patoka J. [et al.]. Associations between polymorphisms in DNA repair genes and glioblastoma. Cancer. Epidemiol. Biomarkers. Prev., 2009, vol. 18, no. 4, pp. 1118-1126. DOI: 10.1158/ 1055-9965.EPI-08-1078

27. Brenner A.V., Linet M.S., Fine H.A., Shapiro W.R., Selker R.G., Black P.M., Inskip P.D. History of allergies and autoimmune diseases and risk of brain tumors in adults. Int. J. Cancer, 2002, vol. 99, no. 22, pp. 252-259. DOI: 10.1002/ijc. 10320

28. Wiemels J.L., Wiencke J.K., Kelsey K.T., Moghadassi M., Rice T., Urayama K.Y., Miike R., Wrensch M. Allergy-related polymorphisms influence glioma status and serum IgE levels. Cancer. Epidemiol. Biomarkers. Prev., 2007, vol. 16, pp. 1229-1235. DOI: 10.1158/1055-9965.EPI-07-0041

29. Rollison D.E., Helzlsouer K.J., Alberg A.J., Hoffman S., Hou J., Daniel R., Shah K.V., Major E.O. Serum antibodies to JC virus, BK virus, simian virus 40, and the risk of incident adult astrocytic brain tumors. Cancer. Epidemiol. Biomarkers. Prev., 2003, vol. 12, pp. 460-463. 
30. Ding D., Zhao A., Sun Z., Zuo L., Wu A., Sun J.Is the presence of HCMV components in CNS tumors a glioma-specific phenomenon? Virol. J., 2019, vol. 16, pp. 96. DOI: 10.1186/s12985-019-1198-5

31. Cobbs C.S., Harkins L., Samanta M., Gillespie G.Y., Bharara S., King P.H., Nabors L.B., Cobbs C.G,. Britt W.J. Human cytomegalovirus infection and expression in human malignant glioma. Cancer. Res., 2002, vol. 62, no. 12, pp. 3347-3350.

32. Stangherlin L.M., Castro F.L., Medeiros R.S., Guerra J.M., Kimura L.M., Shirata N.K., Nonogaki S., Dos Santos C.J., Carlan Silva M.C. Human Cytomegalovirus DNA Quantification and Gene Expression in Gliomas of Different Grades. PLoS One, 2016, vol. 11, pp. e0159604. DOI: 10.1371/journal.pone. 0159604

Berntsson S.G. Primary CNS tumors in adults and environmental factors: an update. Health Risk Analysis, 2020, no. 3, pp. 174-179. DOI: 10.21668/health.risk/2020.3.21.eng

Received: 25.06 .2020

Accepted: 21.09 .2020

Published: 30.09 .2020 